\title{
Sense and nonsense in sensors
}

\author{
J. Hermanides $\cdot$ J. H. DeVries
}

Received: 12 October 2009 / Accepted: 8 December 2009/Published online: 10 January 2010

(C) The Author(s) 2010. This article is published with open access at Springerlink.com

\begin{abstract}
Continuous subcutaneous glucose monitoring (CGM) is a developing technology in the treatment of diabetes mellitus. The first randomised controlled trials on its efficacy have been performed. In several studies, CGM lowered $\mathrm{HbA}_{1 \mathrm{c}}$ in adult patients with suboptimally controlled type 1 diabetes mellitus, when selecting compliant patients who tolerate the device. However, as a preventive tool for hypoglycaemia, CGM has not fulfilled the great expectations. Increasing reimbursement of CGM is expected in the near future, awaiting studies on cost-effectiveness.
\end{abstract}

Keywords Continuous glucose monitoring $\cdot \mathrm{HbA}_{1 \mathrm{c}}$.

Reimbursement $\cdot$ Severe hypoglycaemia

$\begin{array}{ll}\text { Abbreviations } \\ \text { CGM } & \text { Continuous subcutaneous glucose monitoring } \\ \text { CSII } & \text { Continuous subcutaneous insulin infusion } \\ \text { JDRF } & \text { Juvenile Diabetes Research Foundation } \\ \text { RCT } & \text { Randomised controlled trial } \\ \text { SMBG } & \text { Self-monitoring of blood glucose }\end{array}$

Pioneering work of artificially replacing the glucosemonitoring function of the pancreas started in the 1970s [1]. With the introduction of the microdialysis technique in the early 1990s, the future of continuous subcutaneous glucose monitoring (CGM) seemed bright and shiny $[2,3]$. The great expectation was that, by providing the patient

J. Hermanides $\cdot$ J. H. DeVries $(\bowtie)$

Department of Internal Medicine, Academic Medical Centre, P.O. Box 22660, 1100 DD Amsterdam, the Netherlands e-mail: J.H.DeVries@amc.uva.nl with a continuous stream of data and alarms for otherwise unrecognised (nocturnal) hypo- and hyperglycaemia, the $\mathrm{HbA}_{1 \mathrm{c}}$ target of $<7 \%$ was in reach and the main barrier to effective diabetes treatment-the occurrence of severe hypoglycaemia-could be overcome [4-6]. Even more, integrating CGM and continuous subcutaneous insulin infusion (CSII) would mean it would be a matter of time before the closed-loop system would be available [7]. Several years later, the first needle-type sensor became clinically available, though it could only be read out retrospectively [8]. Currently, there are three real-time CGM systems on the market that are approved by the US Food and Drug Administration (FDA) and have the Conformité Européenne (CE) mark: the Freestyle Navigator (Abbott Diabetes Care, Alameda, CA, USA); the Guardian RealTime (Medtronic MiniMed, Northridge, CA, USA); and the DexCom SEVEN (DexCom, San Diego, CA, USA; only available in the USA). All these systems measure glucose in the subcutaneous tissue and provide real-time glucose measurements every 1-5 min. The first randomised controlled trials (RCTs) have now been performed with real-time CGM, prompting the next questions: did the sensor fulfil expectations and is this reflected in the current reimbursement status of the device?

\section{Effect on $\mathrm{HbA}_{1 \mathrm{c}}$}

The first RCT, performed by Deiss and colleagues, investigated a needle-type continuous subcutaneous glucose monitor in patients with poorly controlled type 1 diabetes $\left(\mathrm{HbA}_{1 \mathrm{c}} \geq 8.1 \%\right.$ on intensive treatment) [9]. There was a difference in $\mathrm{HbA}_{1 \mathrm{c}}$ reduction of $0.6 \%$ after 3 months in favour of patients who were instructed to use the device continuously, as compared with patients using conventional 
treatment. In a third arm, patients used CGM biweekly, and this did not result in a significant $\mathrm{HbA}_{1 \mathrm{c}}$ improvement. A subsequent 26 week randomised treat-to-target study performed by Hirsch and coworkers (the STAR 1 trial) yielded disappointing results [10]. There was no significant difference in change in $\mathrm{HbA}_{1 \mathrm{c}}$ between type 1 diabetes patients using CSII randomised to either augmenting their current therapy with CGM or continuing with their standard self-monitoring of blood glucose (SMBG). In both groups, there was a decrease in $\mathrm{HbA}_{1 \mathrm{c}}$ of $0.6-0.7 \%$. That the decreases in $\mathrm{HbA}_{1 \mathrm{c}}$ were comparable in both groups was attributed to intensification of the treatment in both the control and intervention groups. It seems that in an attempt to assure equal attention times in both groups, the control group was treated more intensively than would be feasible in daily practice. In the Juvenile Diabetes Research Foundation (JDRF) study, three different age groups ( $\geq 25$, 15-24 and 8-14 years) were randomised to either CGM or SMBG continuation [11]. All patients had type 1 diabetes and the vast majority were already using CSII. The mean difference in $\mathrm{HbA}_{1 \mathrm{c}}$ change was $0.5 \%$ after 26 weeks in favour of patients using CGM, but this was only in those aged 25 years and older. No significant difference in $\mathrm{HbA}_{1 \mathrm{c}}$ change was detected in the other age groups. In both the STAR 1 and the JDRF trials, the frequency of sensor usage was strongly correlated to the decrease in $\mathrm{HbA}_{1 \mathrm{c}}$. This is in line with the study from Deiss et al. [9] and the recently published RealTrend study [12]. In this latter study, patients administering multiple daily injections and with an $\mathrm{HbA}_{1 \mathrm{c}} \geq$ $8 \%$ at inclusion started with either CSII therapy or sensoraugmented pump therapy for 26 weeks. From a predefined analysis, $\mathrm{HbA}_{1 \mathrm{c}}$ improved compared with the CSII group only in patients using the sensor $>70 \%$ of the time. Unfortunately, patients in the sensor-augmented pump group had already used CGM for 9 days before the baseline $\mathrm{HbA}_{1 \mathrm{c}}$ measurement was performed and therefore the observed $\mathrm{HbA}_{1 \mathrm{c}}$ difference, $0.41 \%$, may have been underestimated. The combination of CGM and CSII has also been investigated in the recently presented Eurythmics trial, where a difference in $\mathrm{HbA}_{1 \mathrm{c}}$ improvement of $1.21 \%$ in favour of the sensor-augmented pump group was found when type 1 diabetes patients $\left(\mathrm{HbA}_{1 \mathrm{c}}\right.$ at entry $\geq 8.2 \%$ ), who were using multiple daily injection therapy and SMBG, were randomised to continuing their current therapy or starting CGM-augmented insulin-pump therapy [13]. It is interesting that the JDRF trial and the Eurythmics trial, both showing a significant $\mathrm{HbA}_{1 \mathrm{c}}$ improvement in the intervention group, confronted patients with a short period of blinded CGM usage at baseline before randomisation. Patients who did not tolerate the device, and therefore would be likely to drop out or be non-compliant during the study course, were at least partly filtered out before randomisation.

\section{Effect on severe hypoglycaemia}

The improvement in $\mathrm{HbA}_{1 \mathrm{c}}$ in the different RCTs was not accompanied by a significant increase in severe hypoglycaemia [9-13]. This seems reassuring, but CGM did not fulfil the expectation that its use would reduce the frequency of severe hypoglycaemic events [14]. Even more, in the STAR 1 trial, the use of CGM was associated with a significant increase in severe hypoglycaemia. This is most likely related to the reduced awareness of auditory and vibratory alarms during hypoglycaemia and non-use of the device during high-risk activities, such as intensive sports. No study so far has shown a decrease in the frequency of severe hypoglycaemia in a CGM arm as compared with the control arm in type 1 diabetes. Indeed, sensors have an inaccuracy of up to $21 \%$ when comparing plasma glucose values with subcutaneous glucose values [15]. This inaccuracy is even more pronounced in the hypoglycaemic range. In addition, the usefulness of the CGM devices for detecting forthcoming hypoglycaemia is limited by a putative physiological delay between the blood glucose and glucose concentration in the subcutaneous tissue, which is accompanied by an instrumental delay of the sensor [16]. In other words, patients need more time to prevent hypoglycaemia, especially when they have hypoglycaemia unawareness. Perhaps the developing technology will result in an alarm function for predicting hypoglycaemia by using the rate of change in glucose in the lower euglycaemic range. For now, CGM is insufficient for the prevention of severe hypoglycaemia.

\section{Costs and reimbursement}

Interestingly, it is the argument of possibly preventing severe hypoglycaemia that has persuaded healthcare organisations in Israel to reimburse CGM use. Children with type 1 diabetes who have experienced more than two severe hypoglycaemic episodes within 1 year are entitled to CGM compensation. In addition, real-time CGM is now covered by the majority of health plans in the USA, including the federal Medicare program. Reimbursement is generally available for type 1 patients with severe hypoglycaemia or those who are not meeting American Diabetes Association $\mathrm{HbA}_{1 \mathrm{c}}$ targets. In the Netherlands and part of Italy, retrospective CGM is currently reimbursed. The Czech Republic covers up to four sensors per year for retrospective CGM and in Sweden, realtime CGM is reimbursed for patients using CSII and having two or more severe hypoglycaemic episodes per year, children who require at least ten plasma glucose tests per $24 \mathrm{~h}$ and patients with $\mathrm{HbA}_{1 \mathrm{c}}>10 \%$ while receiving optimised insulin therapy. The reimbursement indication of hypoglycaemia illustrates that so far, coverage was based on 
feeling rather than the (scarce) evidence. This is not to say that CGM is not able to reduce severe hypoglycaemia, but we need randomised trials in patients at high risk for severe hypoglycaemia (i.e. those suffering from hypoglycaemia unawareness). From the results of the clinical trials to date, we can now argue that CGM offers a clear health benefit, expressed as $\mathrm{HbA}_{1 \mathrm{c}}$ lowering, for type 1 diabetes patients with $\mathrm{HbA}_{1 \mathrm{c}}$ values above $8 \%$. The additional costs for sensors are US $\$ 4380$ per person year compared with US \$550-2740 when using SMBG [17]. Consequently, we need to calculate whether the long-term health benefits of CGM following from ascertained lowering of $\mathrm{HbA}_{1 \mathrm{c}}$ outweigh the costs when compared with standard care with multiple daily injections and/or insulin pumps. A similar comparison was performed by Roze and colleagues indicating that the costeffectiveness of CSII is acceptable [18]. A technical appraisal from the National Institute for Health and Clinical Excellence (England and Wales) seems timely.

\section{Other patient groups}

The application of CGM in patient groups other than those with type 1 diabetes is limited. No trials with adequate duration assessing $\mathrm{HbA}_{1 \mathrm{c}}$ change have been performed for patients with type 2 diabetes [19]. One particular patient group that warrants special attention is pregnant women with diabetes. CGM has proven effective in improving glucose control at the end of pregnancy [20]. It resulted in fewer cases of macrosomia in the offspring, with an odds ratio of 0.36 (95\% CI 0.13 to 0.98 ) [21]. As it concerns a limited time span, reimbursement of CGM in this group should impose no significant financial burden on the healthcare system.

Finally, the use of CGM for treating in-hospital hyperglycaemia could be valuable, and the first randomised studies are awaited. However, the advantage of CGM in this setting may be less evident, as frequent blood sampling is standard practice in the intensive care unit and CGM accuracy may suffer if the circulation is compromised [22].

\section{Conclusion}

CGM with or without CSII has been proven to lower $\mathrm{HbA}_{1 \mathrm{c}}$ in adult patients with type 1 diabetes mellitus and $\mathrm{HbA}_{1 \mathrm{c}}$ values above $8 \%$, when compliant patients who tolerate the device are selected. However, CGM is not the final answer to severe hypoglycaemia. Awaiting a cost-effectiveness analysis, increasing reimbursement of CGM is expected.

Acknowledgements No funding was received for this commentary. We acknowledge N. Papo (Senior Reimbursement Manager, Medtronic
International Trading Sárl, Tolochenaz Switzerland) for providing information on the current global reimbursement status of CGM.

Duality of interest J. H. DeVries is a member of the speakers' bureau for Abbott Diabetes Care and Medtronic and his department has received research support from these companies. J. Hermanides declares that there is no duality of interest associated with this manuscript.

Open Access This article is distributed under the terms of the Creative Commons Attribution Noncommercial License which permits any noncommercial use, distribution, and reproduction in any medium, provided the original author(s) and source are credited.

\section{References}

1. Albisser AM, Leibel BS (1977) The artificial pancreas. Clin Endocrinol Metab 6:457-479

2. Bolinder J, Ungerstedt U, Arner P (1993) Long-term continuous glucose monitoring with microdialysis in ambulatory insulindependent diabetic patients. Lancet 342:1080-1085

3. Bolinder J, Ungerstedt U, Arner P (1992) Microdialysis measurement of the absolute glucose concentration in subcutaneous adipose tissue allowing glucose monitoring in diabetic patients. Diabetologia 35:1177-1180

4. American Diabetes Association (2008) Standards of medical care in diabetes-2008. Diabetes Care 31:S12-S54

5. Cryer PE (2008) The barrier of hypoglycemia in diabetes. Diabetes 57:3169-3176

6. Wentholt IM, Maran A, Masurel N, Heine RJ, Hoekstra JB, DeVries JH (2007) Nocturnal hypoglycaemia in type 1 diabetic patients, assessed with continuous glucose monitoring: frequency, duration and associations. Diabet Med 24:527-532

7. Hanaire H (2006) Continuous glucose monitoring and external insulin pump: towards a subcutaneous closed loop. Diabetes Metab 32:534-538

8. Gross TM, Bode BW, Einhorn D et al (2000) Performance evaluation of the MiniMed continuous glucose monitoring system during patient home use. Diabetes Technol Ther 2:49-56

9. Deiss D, Bolinder J, Riveline JP et al (2006) Improved glycemic control in poorly controlled patients with type 1 diabetes using real-time continuous glucose monitoring. Diabetes Care 29:27302732

10. Hirsch IB, Abelseth J, Bode BW et al (2008) Sensor-augmented insulin pump therapy: results of the first randomized treat-to-target study. Diabetes Technol Ther 10:377-383

11. The Juvenile Diabetes Research Foundation Continuous Glucose Monitoring Study Group (2008) Continuous glucose monitoring and intensive treatment of type 1 diabetes. N Engl J Med 359:14641476

12. Raccah D, Sulmont V, Reznik Y et al (2009) Incremental value of continuous glucose monitoring when starting pump therapy in patients with poorly controlled type 1 diabetes: the RealTrend study. Diabetes Care 32:2245-2250

13. Hermanides J, Nørgaard K, Bruttomesso D et al (2009) Sensor augmented pump therapy substantially lowers $\mathrm{HbA}_{1 \mathrm{c}}$. Diabetologia 52:S43 (Abstract)

14. Cryer PE (2004) Diverse causes of hypoglycemia-associated autonomic failure in diabetes. N Engl J Med 350:2272-2279

15. Wentholt IM, Hoekstra JB, DeVries JH (2007) Continuous glucose monitors: the long-awaited watch dogs? Diabetes Technol Ther 9:399-409 
16. Wentholt IM, Hart AA, Hoekstra JB, DeVries JH (2007) Relationship between interstitial and blood glucose in type 1 diabetes patients: delay and the push-pull phenomenon revisited. Diabetes Technol Ther 9:169-175

17. Pham M (2006) Medtronic. Diabetes: Sizing the market for realtime, continuous blood glucose monitors from MDT, DXCM, and ABT. Available from www.research.hsbc.com/midas/Res/ RDV? $=$ pdf \&key=ate2b8rygn\&name=127057.PDF, accessed 28 September 2009

18. Roze S, Valentine WJ, Zakrzewska KE, Palmer AJ (2005) Healtheconomic comparison of continuous subcutaneous insulin infusion with multiple daily injection for the treatment of type 1 diabetes in the UK. Diabet Med 22:1239-1245
19. Yoo HJ, An HG, Park SY et al (2008) Use of a real time continuous glucose monitoring system as a motivational device for poorly controlled type 2 diabetes. Diabetes Res Clin Pract 82:73-79

20. Landon MB, Gabbe SG, Piana R, Mennuti MT, Main EK (1987) Neonatal morbidity in pregnancy complicated by diabetes mellitus: predictive value of maternal glycemic profiles. Am J Obstet Gynecol 156:1089-1095

21. Murphy HR, Rayman G, Lewis K et al (2008) Effectiveness of continuous glucose monitoring in pregnant women with diabetes: randomised clinical trial. BMJ 337:a1680

22. Sair MPMF, Etherington PJB, Peter Winlove CD, Evans TWM (2001) Tissue oxygenation and perfusion in patients with systemic sepsis. Crit Care Med 29:1343-1349 